\title{
The heat flow during the formation of ribbon terrains on Venus
}

\author{
Javier Ruiz* \\ Instituto de Astrofísica de Andalucía, CSIC, Camino Bajo de Huétor 50, 18008 Granada, Spain \\ Received 19 January 2007; received in revised form 29 April 2007; accepted 11 May 2007 \\ Available online 24 May 2007
}

\begin{abstract}
Ribbons are regularly spaced, between 2 and $6 \mathrm{~km}$, troughs that exist on venusian tesserae, which are mainly located in, and characterize to, venusian crustal plateaus. Independent of the geological or temporal relations with other features, regularly and similarly spaced ribbons on several tesserae strongly suggest a thermal control on the thickness of the deformed layer. This can be used to constraint the heat flow at the time of ribbon formation, which holds important implications for the viability of the hypotheses that address the origin and evolution of crustal plateaus. For a brittle-ductile transition $\sim 1-3 \mathrm{~km}$ deep (as proposed from ribbon spacing), realistic strain rates, and a present-day surface temperature of $740 \mathrm{~K}$, the implied heat flow is very high, $130-780 \mathrm{~mW} \mathrm{~m}^{-2}$. If Venus has experienced higher surface temperatures due to climate forcing by massive volcanism, then the heat flow could be greatly reduced. For surface temperatures of $850-900 \mathrm{~K}$ the heat flow is $190-560,60-230$ and $20-130 \mathrm{~mW} \mathrm{~m}^{-2}$ for brittle-ductile transition depths of 1 , 2 and $3 \mathrm{~km}$, respectively. Heat flow values around $80-100 \mathrm{~mW} \mathrm{~m}^{-2}$ are reasonable for venusian hotspots, based on terrestrial analogs, but hardly consistent with coldspot settings. High surface temperatures are also required to maintain the crustal solidus deeper than a few kilometers during the formation of ribbon terrains. For the obtained heat flows, a solidus deeper than $\sim 30 \mathrm{~km}$ (the likely mean value for the crustal thickness) is difficult to achieve. This suggests that a substantial proportion of the crust beneath crustal plateaus was emplaced subsequently to the time when ribbon terrains were formed. Alternatively, at that time a magma reservoir inside the crust could have existed.
\end{abstract}

Keywords: Venus geodynamics; Crustal plateaus; Heat flow; Ribbon terrains; Climate evolution

\section{Introduction}

Ribbons are nearly rectilinear, have large aspect ratios and there are closely spaced pairs of troughs and ridges on many Venus' tesserae (Hansen and Willis, 1996, 1998). Tessera terrains constitute the locally oldest surface unit on Venus (e.g., Price and Suppe, 1994; Basilevski and Head, 1995), although diverse tesserae could have different ages (e.g., Hansen et al., 1999). Tessera terrains are characterized by at least two sets of intersecting tectonic structures, elevated topography, and high surface roughness, and are mainly located in crustal plateaus (Barsukov et al., 1986; Basilevski et al., 1986; Ivanov and Head, 1996; Hansen et al., 1997). Ribbons are usually interpreted as extensional

\footnotetext{
*Present address: Museo Nacional de Ciencias Naturales, CSIC, José Gutiérrez Abascal 2, 28006 Madrid, Spain. Tel.: + 34916138145; fax: +34915644740 .

E-mail address: jaruiz@geo.ucm.es
}

features, but there is no consensus about their structural and temporal relations with other geological features (e.g., Gilmore et al., 1998; Hansen et al., 2000). Two types of ribbon have been proposed to exist on the basis of the deduced mode of fracturing associated with their formation (Hansen and Willis, 1998): tensile-fracture and shearfracture ribbons, the latter being the more abundant type.

Regularly spaced structural features are related to the thickness of a strong (brittle) layer above a weaker layer acting as a level of decollement (e.g., Smith, 1977; Fletcher and Hallet, 1983). The rheological decollement associated with ribbon formation could be controlled by compositional stratification, but it is hard to have a compositional layer of closely uniform thickness on distances of, at least, hundreds of kilometers, more so as regularly and similarly spaced ribbons are observed on spatially separated tesserae. So, independently of the structural and temporal relations between ribbons and folds, this implies that ribbon spacing was related to the thermally controlled 
brittle-ductile transition depth (Hansen and Willis, 1998; Ghent and Hansen, 1999; Ghent and Tibuleac, 2002), which is the depth under which the temperature is sufficiently high to permit ductile creep to dominate over brittle failure. Thus, ribbon spacing can be used to constrain the thermal state, and hence heat flow, of the upper crust at the time when these features were formed.

In this work, I use the spacing of shear-fracture ribbons and a dry diabase rheology to calculate surface heat flows representative of the time (and place) of ribbon terrains formation. Tensile-fracture ribbons are not taken into account for the calculations because they are relatively rare and there is no consensus about the interpretation of these features (this question is beyond the scope of the present paper). Calculations are first presented for the present-day Venus surface temperature of $740 \mathrm{~K}$, followed by the effect of increasing the surface temperature. The obtained results are compared with other heat flow estimations for Venus. In addition, the depth to the solidus of the crust, which limits the crustal thickness, is calculated for the conditions of ribbon terrain formation. These calculations and comparisons provide insight about the thermal and climatic evolution of Venus, and constrain geodynamic models of tessera and crustal plateau formation.

\section{Ribbon terrains and crustal plateaus}

The term ribbon is used to describe a "class" of closely spaced, parallel, and alternating radar-dark and radarbright lineaments (for a detailed description see Hansen and Willis, 1996, 1998). Ribbons are interpreted as pairs of troughs and highs, bounded by steep walls, originated by extension of the crust, which show a similar pattern and orientation over distances of up to several hundreds of kilometers. Ribbons are perpendicular to diverse scale folds, and parallel to larger, complex grabens (e.g., Hansen et al., 1999). This pattern defines the tectonic fabric of tessera terrains (Barsukov et al., 1986; Basilevski et al., 1986). The majority of tesserae are found on crustal plateaus, but there are tessera inliers outcropping in the venusian lowlands, and interpreted as remnants of collapsed crustal plateaus (e.g., Bindschadler et al., 1992; Ivanov and Head, 1996; Hansen and Willis, 1998).

Venusian crustal plateaus are large $(\sim 1500-2500 \mathrm{~km}$ in diameter), roughly circular or elongate, high standing and steep slope bounded features. The altitude of their surface is $\sim 0.5-4 \mathrm{~km}$ higher than the adjacent terrains (e.g., Hansen, 2006). Also, crustal plateaus are characterized by tessera terrains, which are defined by the presence of at least two different sets of intersecting tectonics lineaments (e.g., Bindschadler et al., 1992; Ivanov and Head, 1996; Hansen et al., 1997).

The absolute thickness of the venusian crust is poorly constrained due to the limited resolution of the available topography and gravity data, but a mean crustal thickness value of $\sim 30 \mathrm{~km}$ is usually cited (Grimm and Hess, 1997). Topography of crustal plateaus is isostatically, or near- isostatically, compensated, which, along the high standing topography, suggests a thickened crust beneath them (Smrekar and Phillips, 1991; Simons et al., 1997; Anderson and Smrekar, 2006). A recent admittance study (Anderson and Smrekar, 2006) finds best fits for top loading and thin effective elastic thicknesses in crustal plateaus, which support a crust thicker than the planetary average. The admittance modeling by Anderson and Smrekar (2006) suggest a crust $\sim 10-40 \mathrm{~km}$ thick, beneath crustal plateaus. The observed topography of crustal plateaus was likely originated through a complex evolution (e.g., Nunes et al., 2004). For this reason, deductions about crustal thickness or the compensation mode based on the present-day topography or admittance are not necessarily valid for the time of ribbon terrains formation.

There are several hypotheses that address the origin and evolution of venusian crustal plateaus. Crustal plateaus could have originated related to zones of lithospheric downwelling and compression (e.g., Bindschadler and Parmentier, 1990; Bindschadler et al., 1992); in this scenario, ribbons are the result of late extension due to gravitational collapse of the thickened crust (Gilmore et al., 1998), with folds being the oldest deformation structures on tesserae. Alternatively, crustal plateaus could have formed related to the upwelling of mantle plumes beneath a thin lithosphere (e.g., Hansen and Willis, 1998; Phillips and Hansen, 1998; Hansen et al., 1999), with ribbons predating long-wavelength $(\sim 15-30 \mathrm{~km})$ folds, but may be contemporaneous to short-wavelength $(\sim 1-2 \mathrm{~km})$ folds. In this model, the different spacing of ribbons and folds would be due to the deepening of the brittle-ductile transition with time because the cooling of the crust above the emplaced upwelling; shallow deformation would be favored by a surface temperature higher than that currently observed. These two hypotheses have very different implications for the thermal state of the lithosphere when crustal plateaus (and specifically ribbons) formed. Because downwelling and upwelling represent coldspot and hotspots, respectively, a part of the downwelling vs. upwelling debate on crustal plateaus formation has focused on that specific issue (e.g., Gilmore et al., 1998; Hansen et al., 2000).

Recently, Hansen (2006) argued that both hypotheses have difficulties in addressing the complete suite of contractional and extensional features on crustal plateaus; she presented evidence that the shortest wavelength folds predate or formed synchronously with ribbons in eastern Ovda Regio. As an alternative hypothesis, Hansen (2006) proposed that crustal plateaus formed (as surface "scum") on huge lava ponds, which may have been originated from large impacts causing massive melting in the mantle. This scenario can be considered as a hotspot hypothesis.

The only previous work estimating heat flows from ribbons was performed by Gilmore et al. (1998). These workers used geometrical criteria to estimate the decollement depth of ribbons considered as grabens. For a brittle-ductile transition depth of $1-2 \mathrm{~km}$, these authors found heat flows of $300-800 \mathrm{~mW} \mathrm{~m}^{-2}$ for dry diabase 
rheologies. These values are similar to those observed near some terrestrial mid-ocean ridges (e.g., Pollack et al., 1993), and clearly higher than other estimations for Venus (see Section 4). Alternatively, Gilmore et al. (1998) obtained heat flows lesser than $\sim 100 \mathrm{~mW} \mathrm{~m}^{-2}$ by using a standard wet diabase rheology. In addition, these authors found heat flows of $600-800 \mathrm{~mW} \mathrm{~m}^{-2}$ for the formation of tensile fractures $\leqslant 1 \mathrm{~km}$ deep. Gilmore et al. (1998) discounted both tensile-fracture interpretation of ribbon structures and the upwelling plume hypothesis, and they noted that heat flow values obtained for wet diabase are similar to average present-day terrestrial or (proposed) venusian values, and therefore acceptable for ribbon terrain formation. But the use of a dry rheology is usually assumed for Venus, whereas a wet rheology seems unrealistic, because high temperatures and extensive volcanism suggest extremely dry conditions for the venusian lithosphere (e.g., Kaula, 1990; Brown and Grimm, 1997; Phillips et al., 1997).

\section{Heat flows from the brittle layer thickness}

Several works have reported ribbon spacing of a few kilometers (Bindschadler et al., 1992; Hansen and Willis, 1996, 1998; Ghent and Hansen, 1999; Ghent and Tibuleac, 2002). The most globally extensive and systematic study was performed by Ghent and Tibuleac (2002), who found that ribbon spacing typically ranges between 2 and $6 \mathrm{~km}$. The spacing of regularly spaced structural features can be related to the thickness of the strong upper layer. For extension, theoretical analyses, analog model experiments, and observation of terrestrial settings usually obtain periodical brittle deformation, with alternating horst and grabens, characterized by a spacing/brittle layer thickness ratio of 2-4 (e.g., Smith, 1977; Fletcher and Hallet, 1983; Zuber et al., 1986; Martinod and Davy, 1992; Corti, 2005). Thus, Ghent and Tibuleac (2002) obtained a thickness of $\sim 1-3 \mathrm{~km}$ for the brittle layer at the time when (and the places where) the ribbon terrain formed. It is worth mentioning that the so obtained brittle layer thicknesses are upper limits, because extension can substantially increase the observed spacing. An increase in spacing leads to propose a thicker brittle layer, which in turn would imply an underestimation of the calculated heat flows. The thickness of the brittle layer is constrained by the brittle-ductile transition, which indicates the depth at which the brittle and ductile strengths are equal. The temperature at the brittle-ductile transition depth can be obtained from the temperature dependence of ductile strength. In turn, the knowledge of the temperature at the brittle-ductile transition depth allows the calculation of the surface heat flow by matching a temperature profile (e.g., Ruiz and Tejero, 2000; Ruiz et al., 2006b).

The brittle strength is a function of lithostatic pressure. For zero pore pressure, this can be written in a general form as $\left(\sigma_{1}-\sigma_{3}\right)_{\mathrm{b}}=\alpha P$, where $\alpha$ is a coefficient depending on the stress regime and $P$ is the pressure; for pure tension, appropriate for shear-fracture ribbons, $\alpha=0.8$ (e.g., Brace and Kohlstedt, 1980; Watts, 2001). In the case of Venus, and for shallow depths, the atmospheric pressure must be taken into account, and therefore

$\left(\sigma_{1}-\sigma_{3}\right)_{\mathrm{b}}=\alpha\left(\rho g z+P_{\mathrm{s}}\right)$,

where $\rho$ is the crust density (taken as $2900 \mathrm{~kg} \mathrm{~m}^{-3}$ ), $g$ is the acceleration due to gravity ( $8.9 \mathrm{~m} \mathrm{~s}^{-2}$ for Venus), $z$ is the depth, and $P_{\mathrm{s}}$ is the atmospheric pressure at the venusian surface (9.2 MPa). The ductile strength is given by

$\left(\sigma_{1}-\sigma_{3}\right)_{\mathrm{d}}=\left(\frac{\dot{e}}{A}\right)^{1 / n} \exp \left(\frac{Q}{n R T}\right)$,

where $\dot{e}$ is the strain rate, $A, p$, and $n$ are laboratorydetermined constants, $Q$ is the activation energy of creep, $R$ ( $=8.3145 \mathrm{~J} \mathrm{~mol}^{-1} \mathrm{~K}^{-1}$ ) is the gas constant, and $T$ is the absolute temperature. Given the extremely dry conditions of Venus, a dry diabase rheology seems most appropriate. For creep parameters for dry diabase $I$ use $A=30 \mathrm{MPa}^{-n} \mathrm{~s}^{-1}, n=4.7$, and $Q=485 \mathrm{~kJ} \mathrm{~mol}^{-1}$; these parameter values give the mean strength between those obtained for dry Columbia and Maryland diabases according to the experimental flow laws in Mackwell et al. (1998), which differ in the value of $A$. The use of dry Columbia ( $\left.A=190 \mathrm{MPa}^{-n} \mathrm{~s}^{-1}\right)$ or Maryland $\left(A=8 \mathrm{MPa}^{-n} \mathrm{~s}^{-1}\right)$ diabases only decreases or increases, respectively, the obtained heat flow by about $10 \%$, which is not important for the conclusions in this study. The actual strain rates related to ribbon formation are unknown, but a wide range of values, between $10^{-17}$ and $10^{-14} \mathrm{~s}^{-1}$, is used. This range is based on several considerations: Grimm (1994) estimated mean strain rates of $10^{-19}-10^{-18} \mathrm{~s}^{-1}$ for the time postdating the resurfacing of Venus, which implies that the stages of active deformation must have been characterized by faster strain rates; strain rates are typically $10^{-17}-10^{-15} \mathrm{~s}^{-1}$ for extensional deformation on the Earth (Newman and White, 1997); an analysis of the growth of long-wavelength $(\sim 15-20 \mathrm{~km})$ folds in tesserae obtained a preferred strain rate range of $\geqslant 10^{-16}-10^{-15} \mathrm{~s}^{-1}$ for fold wavelengths of $\leqslant 20 \mathrm{~km}$ (Brown and Grimm, 1997), although these folds probably originated at different times and conditions than the ribbon structures addressed herein.

The temperature at the brittle-ductile transition is obtained from equating Eqs. (1) and (2) for $z=z_{\mathrm{BDT}}$. The heat flow, assuming a linear thermal gradient, is given by

$F=\frac{k\left(T_{\mathrm{BDT}}-T_{\mathrm{s}}\right)}{z_{\mathrm{BDT}}}$,

where $k$ is the thermal conductivity, $T_{\mathrm{BDT}}$ is the temperature at the brittle-ductile transition, and $T_{\mathrm{s}}$ is the surface temperature. The thermal conductivity is taken as $2 \mathrm{~W} \mathrm{~m}^{-1} \mathrm{~K}^{-1}$, a typical value for basaltic rocks (Beardsmore and Cull, 2001). Additionally, at temperatures of several hundreds of degrees centigrade, which are similar to those in the venusian surface, a wide variety of crustal rocks have thermal conductivities very close to this value 
(e.g., Bonner et al., 2003). So, a thermal conductivity significantly different from the value used here is unlikely. If crustal heat sources (which can include heat lost from a cooling crust) are taken into account in the calculations, the obtained surface heat flow values would be higher (Ruiz et al., 2006a, b); however this effect is limited to the case of ribbon terrains formation, because of the shallow brittle-ductile transition implied. The use of linear thermal gradients is useful at this point, although I will return to this question later.

\section{Results for the present-day surface temperature}

Fig. 1 shows the heat flow as a function of the brittle-ductile transition depth and strain rate, calculated for the present-day surface temperature, $740 \mathrm{~K}$. The decrease in the surface temperature and pressure with altitude would reduce the obtained heat flows, but even for the highest plateau altitude this effect is lesser than $10 \%$, and is therefore ignored here.

The total range of heat flow consistent with $z_{\text {BDT }}=1-3 \mathrm{~km}$ is very broad, $\sim 130-780 \mathrm{~mW} \mathrm{~m}^{-2}$, mainly due to uncertainties in both the spacing/brittle layer thickness ratio and strain rate. The lower bound is lower than the value obtained for dry diabase rheologies by Gilmore et al. (1998; see their Fig. 18), because these authors limited their calculations to $z_{\mathrm{BDT}} \leqslant 2 \mathrm{~km}$ and to a relatively fast strain rate of $10^{-15} \mathrm{~s}^{-1}$. For example, for $z_{\mathrm{BDT}}=2 \mathrm{~km}$ and $\dot{e}=10^{-17}-10^{-14} \mathrm{~s}^{-1}$, the heat flow is $220-340 \mathrm{~mW} \mathrm{~m}^{-2}$. In any case, the heat flow values obtained for the ribbon terrain are clearly higher than whichever other estimation of surface heat flow is proposed for Venus. For example, thermal gradients $(\mathrm{d} T / \mathrm{d} z)$ deduced from geological and geophysical indicators (see Phillips et al., 1997) or modeling of folds growth (Brown and Grimm, 1997) are lower than $30 \mathrm{~K} \mathrm{~km}^{-1}$ (linear lithospheric thermal gradients and heat flow can easily be

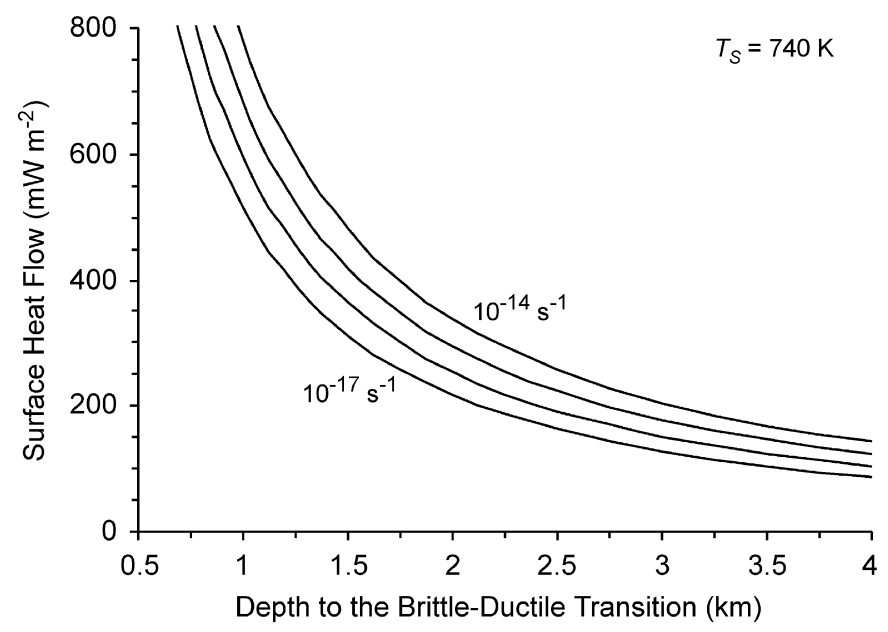

Fig. 1. Heat flow values as a function of the depth to the brittle-ductile transition, at the time when ribbon terrains were formed, calculated for a (present-day) surface temperature of $740 \mathrm{~K}$. In all the figures, the curves are drawn for $10^{-17}, 10^{-16}, 10^{-15}$ and $10^{-14} \mathrm{~s}^{-1}$. converted: heat flows (thermal gradients) are obtained from thermal gradients (heat flows) by multiplying (divide) by the thermal conductivity. For $\mathrm{d} T / \mathrm{d} z=30 \mathrm{~K} \mathrm{~km}^{-1}$ and $k=2 \mathrm{~W} \mathrm{~m}^{-1} \mathrm{~K}^{-1}$, the heat flow is $60 \mathrm{~mW} \mathrm{~m}^{-2}$.) For comparison, convective models for Venus give heat flows in the range between $\sim 10$ and $\sim 60 \mathrm{~mW} \mathrm{~m}^{-2}$ (e.g., Solomatov and Moresi, 1996; Schubert et al., 1997). So, with the independence of structural, genetic, and temporal relations of ribbons with other features, the thermal conditions that accompanied the formation of ribbon terrains were different from those conditions that prevailed when other features were formed, with the exception, maybe, of short-wavelength folds on tesserae (e.g., Hansen, 2006).

Because of the similarity of mass, radius and density with the Earth, it has been common to extrapolate the terrestrial heat flow to Venus, obtaining values between $\sim 63$ and $78 \mathrm{~mW} \mathrm{~m}^{-2}$ (Solomon and Head, 1982; Turcotte, 1995; Brown and Grimm, 1999), depending on the value taken for the Earth. If the mean terrestrial heat flow deduced from the last global compilation, $87 \mathrm{~mW} \mathrm{~m}^{-2}$ (Pollack et al., 1993), is used, then $78 \mathrm{~mW} \mathrm{~m}^{-2}$ is obtained for Venus. It must however be noted that a substantial fraction of the terrestrial heat flow is due to plate tectonics, and therefore this value can be taken as an upper limit. If the total present-day radiogenic power of the Earth, estimated as $\sim 1.9 \times 10^{13} \mathrm{~W}$ (McDonough and Sun, 1995), equivalent to $37 \mathrm{~mW} \mathrm{~m}^{-2}$, is scaled to Venus, an average surface heat flow of $34 \mathrm{~mW} \mathrm{~m}^{-2}$ is obtained. According to McKinnon et al. (1997), the average model age of the entire surface is $\sim 750 \mathrm{Ma}$; based on this result, Phillips and Hansen (1998) estimate an average model age of $\sim 900 \mathrm{Ma}$ for tesserae. Taking bulk radiogenic isotopes abundances and decay constants as in Turcotte and Schubert (2002), the total radiogenic power was 1.16 and 1.20 times the present-day value, which implies equivalent heat flows of 39 and $41 \mathrm{~mW} \mathrm{~m}^{-2}, 750$ and $900 \mathrm{Ma}$ ago, respectively. Thus, if terrestrial values are somewhat applicable to Venus, the mean venusian heat flow at the time of ribbon terrains formation was probably between 40 and $80 \mathrm{~mW} \mathrm{~m}^{-2}$. However, the thermal evolution of Venus is a complicated matter (e.g., Schubert et al., 1997), and these values must be taken cautiously.

Phillips et al. (1997) proposed that a heat flow higher than average should be expected for a venusian hotspot, as it is the case for the Earth. For example, geologically active zones on continental areas can reach $\sim 100 \mathrm{~mW} \mathrm{~m}^{-2}$ (e.g., Cermak, 1993). If ribbon terrains effectively formed above hot thermal anomalies, similar values of surface heat flow should not be surprising. Only for a brittle-ductile transition depth close to $3 \mathrm{~km}$ (the upper limit of the range suggested from ribbon spacing; Ghent and Tibuleac, 2002), surface heat flows, as shown in Fig. 1, approach $\sim 100 \mathrm{~mW} \mathrm{~m}^{-2}$. In any case, the results presented in Fig. 1 are inconsistent with a coldspot-related origin for ribbon terrains, given that a coldspot setting implies surface heat flows lower than average. 
Hansen (2006) presented evidence that the shortest wavelength $(\sim 0.5-0.9 \mathrm{~km})$ folds in tessera terrain, which are more closely spaced than ribbons, predated or accompanied ribbon formation at eastern Ovda Regio. Also, spacing/brittle layer thickness ratios are greater for contractional features, suggesting a thinner brittle layer. However, this does not necessarily imply a higher heat flow, because brittle strength is greater for compression (e.g., Brace and Kohlstedt, 1980; Watts, 2001), whereas ductile strength is not dependent on stress regime: temperatures in the brittle-ductile transition depth are lower for compression than for tension. Moreover, progressive shortening decreases the spacing (see Hansen, 2006), so spacing/brittle layer thickness for contractional and extensional features cannot be robustly compared.

\section{Results for increased surface temperatures}

It has been suggested that global volcanic events could affect the climatic history of Venus, maybe leading to episodic surface temperatures as high as $850-900 \mathrm{~K}$ (Bullock and Grinspoon, 1996, 2001), or even as $1000 \mathrm{~K}$ (Phillips et al., 2001). Phillips and Hansen (1998) and Hansen et al. (2000) have argued that surface temperatures of $900-1000 \mathrm{~K}$, during the time of ribbon terrain formation would relax the thermal requirements for ribbon formation related to a brittle-ductile transition a few kilometers deep.

Heat flows values calculated using Eq. (3) linearly decrease with increase in surface temperature. Fig. 2 shows the heat flow as a function of the surface temperature (taken to be between 700 and $1000 \mathrm{~K}$ ) for $z_{\mathrm{BDT}}$ values of 1 , 2 and $3 \mathrm{~km}$. For $T_{\mathrm{s}}=850-900 \mathrm{~K}$, the heat flow is $190-560$, 60-230, and $20-130 \mathrm{~mW} \mathrm{~m}^{-2}$ for $z_{\mathrm{BDT}}$ values of 1,2 and $3 \mathrm{~km}$, respectively; these values are much lower than the values obtained for the present-day surface temperature. So, if the venusian surface environment was, at the time of ribbon terrain formation, $\sim 100-150$ degrees hotter than today, the obtained heat flows could be roughly consistent with venusian hotspots (although it does not favor any specific hotspot model), but hardly consistent with coldspot settings. As an example, Fig. 3 shows the surface temperature obtained for a heat flow of $100 \mathrm{~mW} \mathrm{~m}^{-2}$ (a reasonable value for venusian hotspots; see Section 4), as a function of the brittle-ductile transition depth. A surface temperature of $850-900 \mathrm{~K}$ is obtained for $z_{\mathrm{BDT}}=1.5-3.7 \mathrm{~km}$; this brittle-ductile transition depth range is similar to that proposed from ribbon spacing (Ghent and Tibuleac, 2002).

On the other hand, finite element modeling by Ghent et al. (2005) suggests that the formation of short-wavelength folds on tesserae cannot be explained only by thermal control of the lithosphere properties, including surface temperature, but the implications of that work for extensional ribbons are not clear.
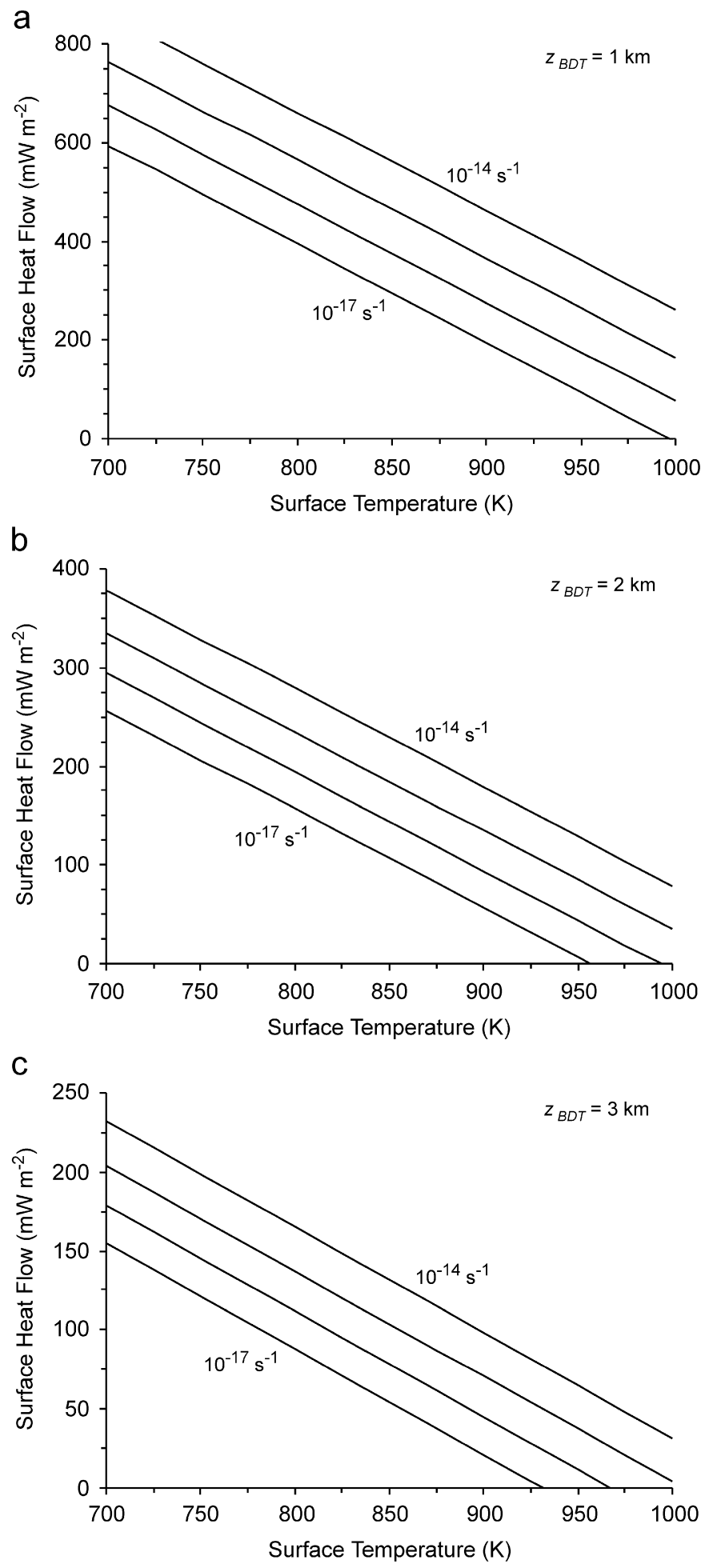

Fig. 2. Surface heat flow as a function of the surface temperature, calculated for brittle--ductile transition depths of (a) $1 \mathrm{~km}$, (b) $2 \mathrm{~km}$, and (c) $3 \mathrm{~km}$.

\section{Depth to the solidus}

High heat flows and high surface temperatures favor melting inside the lower crust (e.g., Montési and Zuber, 2002), which should limit the thickness of the crust or the 


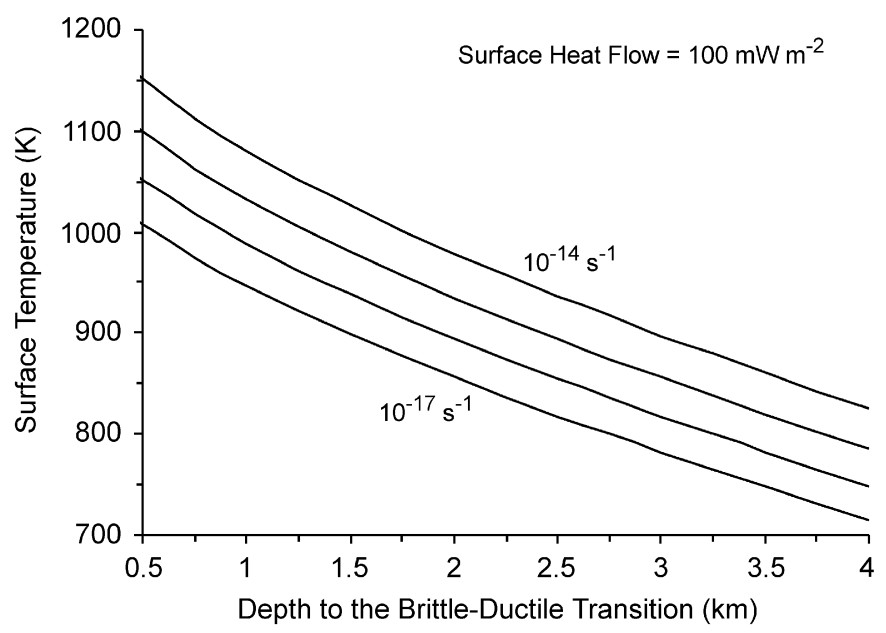

Fig. 3. Surface temperature, as a function of the depth to the brittle-ductile transition, consistent with a surface heat flow of $100 \mathrm{~mW} \mathrm{~m}^{-2}$. This value is roughly representative of heat flow highs in terrestrial continental areas.

thickness of the solid layer above a lava pond (Hansen, 2006). Montési and Zuber (2002) have calculated thermal gradients for which the solidus of alkali and dry MORB basalts, and dry gabbro, are reached at a depth of $30 \mathrm{~km}$ (the value usually cited for the mean crustal thickness of Venus; Grimm and Hess, 1997). For $T_{\mathrm{s}}=740 \mathrm{~K}$ that thermal gradient is $\sim 28-33 \mathrm{~K} \mathrm{~km}^{-1}$ (corresponding to a heat flow of $\sim 56-66 \mathrm{~mW} \mathrm{~m}^{-2}$ for a thermal conductivity of $2 \mathrm{~W} \mathrm{~m}^{-1} \mathrm{~K}^{-1}$ ), whereas for $T_{\mathrm{s}}=850-900 \mathrm{~K}$ it is $\sim 20-27 \mathrm{~K} \mathrm{~km}^{-1}$ (or equivalently, $F \sim 40-54 \mathrm{~mW} \mathrm{~m}^{-2}$ ). The heat flows in Figs. 1 and 2 would therefore imply melting within the crust for an important part of the explored parameter space.

Here I calculate the solidus temperature of dry MORB basalt, assumed as an analog for the venusian crust, from

$T_{\text {solidus }}(\mathrm{K})=1330+0.075 P(\mathrm{MPa})$,

relation based on the data in Yasuda et al. (1994). To calculate solidus depth, crustal heat sources must be taken into account, because the solidus could be significantly deeper than the brittle-ductile transition related to ribbon formation. The consideration of crustal heat sources in heat flow calculations performed from temperature-indepth indicators (1) increases the obtained surface heat flow values, and (2) decreases the temperature in levels deeper than the depth to the indicator used (Ruiz et al. $2006 \mathrm{a}, \mathrm{b})$. If heat sources homogeneously distributed are assumed, the temperature profile is given by

$T_{\mathrm{z}}=T_{\mathrm{s}}+\frac{F z}{k}-\frac{H z^{2}}{2 k}$,

where $H$ is the volumetric heating rate. Radiogenic element measurements presented in Surkov et al. (1987) for MORB basalt-like Venera 9 and 10, and Vega 1 and 2 sites, give mean abundances of $0.6 \mathrm{ppm}$ for uranium, $2 \mathrm{ppm}$ for thorium, and $0.4 \%$ for potassium. By using decay constants and isotope partitioning as in Turcotte and Schubert (2002), $\quad H=0.42 \mu \mathrm{W} \mathrm{m}^{-3}$ for $750 \mathrm{Ma}$, or $H=0.43 \mu \mathrm{W} \mathrm{m}^{-3}$ for $900 \mathrm{Ma}$ is obtained.

From Eq. (5), and taking $z=z_{\mathrm{BDT}}$, it is obvious that surface heat flow values obtained from Eq. (3) must be increased in an amount equal to $z_{\mathrm{BDT}} H / 2$ if crustal heat sources are considered. This amount is very modest for the values of $H$ indicated above, and it can be calculated as $\sim 0.21 z_{\mathrm{BDT}} \mathrm{mW} \mathrm{m}^{-2}$ if $z_{\mathrm{BDT}}$ is given in kilometers. On the other hand, it is also clear that the subcrustal heat flow (the heat flow from the mantle) is $F-z_{\text {crust }} H$, where $z_{\text {crust }}$ is the depth to the crust base; this implies a mantle heat flow $\sim 0.42 z_{\text {crust }} \mathrm{mW} \mathrm{m}^{-2}$, if $z_{\text {crust }}$ is given in kilometers, lower than the surface heat flow. These effects can be important for relatively low values of surface heat flow.

Taking into account that surface heat flows increased, with respect to those calculated in previous sections, as indicated above, Eq. (5) can be used to calculate the basalt solidus. Fig. 4 shows the depth to the solidus of dry basalt for $z_{B D T}=2 \mathrm{~km}$ (a representative value for the brittleductile transition depth when ribbon terrains formed), as a function of the surface temperature. For higher surface temperatures, the basalt solidus is deeper due to the lower heat flow obtained for a given brittle-ductile transition depth (see Ruiz, 2003). For surface temperatures close to the present-day value of $740 \mathrm{~K}$, the basalt solidus lies close to the surface. For surface temperatures of $850-900 \mathrm{~K}$, the basalt solidus lies between 8 and $25 \mathrm{~km}$, except for the slowest strain rates considered, for which it could be even as deep as $66 \mathrm{~km}$. Complementarily, Fig. 5 shows the depth to the solidus of dry basalt for $T_{\mathrm{s}}=875 \mathrm{~K}$ in terms of the depth to the brittle-ductile transition: solidus depths $\geqslant 30 \mathrm{~km}$ are only obtained for $z_{B D T} \geqslant \sim 3 \mathrm{~km}$.

Thus, the conditions for a dry basalt solidus deeper than the average thickness of the crust are very difficult to achieve. These results would be more straightforward for a thickened crust beneath crustal plateaus. This could imply

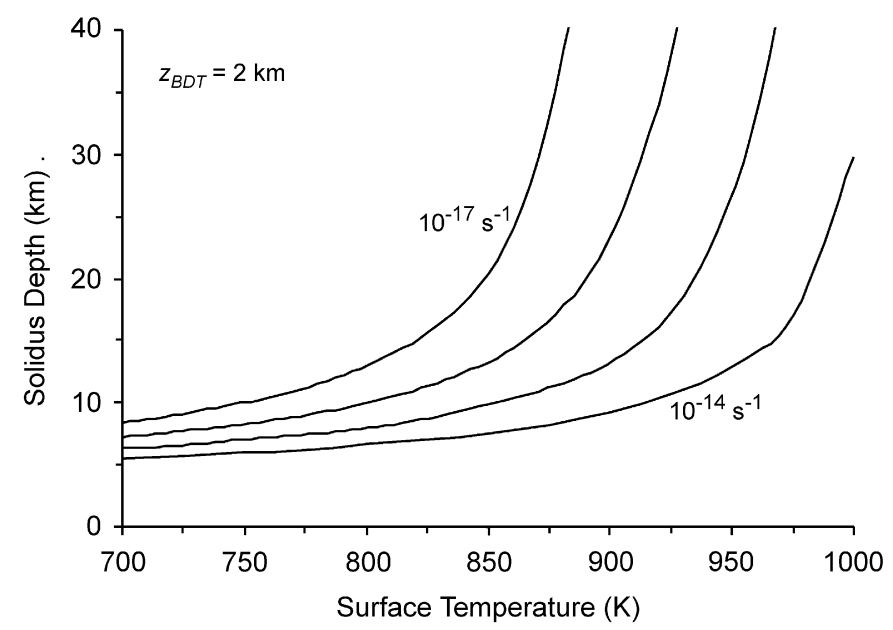

Fig. 4. Depth to the solidus of the dry MORB basalt, assumed as an analog for the venusian crust, calculated for a brittle-ductile transition $2 \mathrm{~km}$ deep, and shown as a function of the surface temperature. 


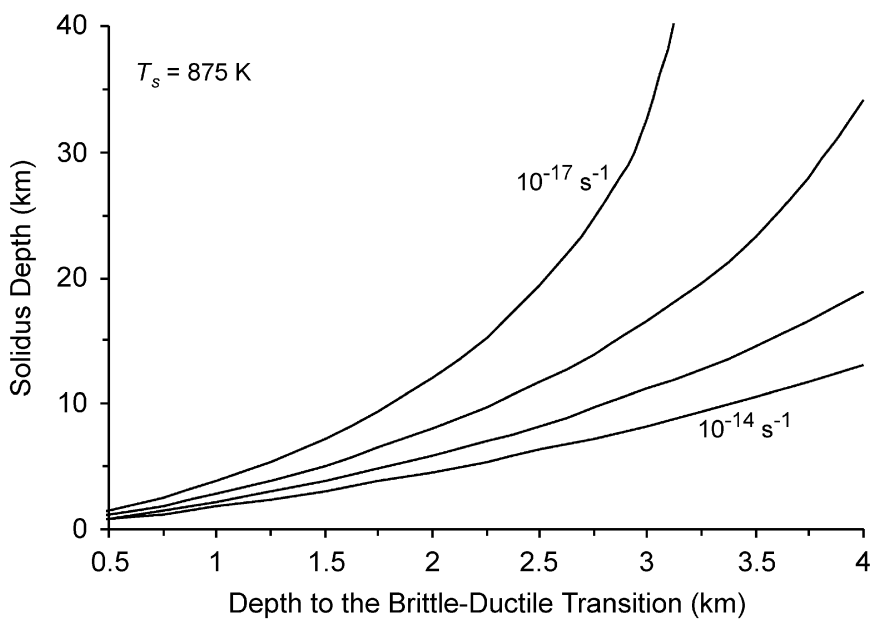

Fig. 5. Depth to the solidus of the dry MORB basalt, calculated for $T_{\mathrm{s}}=875 \mathrm{~K}$, as a function of the brittle-ductile transition depth.

that a substantial proportion of the venusian crust was emplaced subsequently to the formation of the ribbon terrains, which should not be a problem if ribbon terrains formed above upwelling plumes (e.g., Phillips et al., 1991). Alternatively, a magma reservoir inside the crust could have existed, maybe in the line suggested by Hansen (2006).

\section{Conclusions}

The presence of regularly and similarly spaced ribbons on tessera terrains implies a thermal control for the base of the upper strong layer, which should correspond to the brittle-ductile transition depth. Heat flows calculated for ribbon terrains (at the time of ribbon formation) using the present-day surface temperature of $740 \mathrm{~K}$ are very high, ranging from similar to clearly higher than the values typically found close to mid-ocean ridges. Increasing surface temperatures as predicted by some models of climate forcing due to massive volcanic activity reduces the surface heat flow to reasonable values for venusian hotspots, except for the lowermost part of the range used for the brittle-ductile transition depth, or the fastest strain rates taken as potentially representative. Otherwise, the results presented here are hardly consistent with a coldspot setting for ribbon terrain formation (and hence for crustal plateaus evolution): a coldspot hypothesis for ribbon terrains formation requires a heat flow lower than the global average. Indeed, heat flows lower than the mean values obtained by scaling of terrestrial radiogenic power or surface heat flow are only obtained for the uppermost part of the range considered for both surface temperature and brittle-ductile transition depth, and slow strain rates. Finally, the estimated depth to the crustal solidus strongly suggests that at tessera regions, when ribbons terrains were formed, either the crust was thinner than today or a magma reservoir existed inside the crust.

\section{Acknowledgments}

I thank Iván López, Miguel Angel López-Valverde, Duncan Young and an anonymous referee for their helpful comments, suggestions and reviews. This work was supported by an I3P contract with the Spanish Consejo Superior de Investigaciones Científicas (CSIC) co-financed by the Fondo Social Europeo.

\section{References}

Anderson, F.S., Smrekar, S.E., 2006. Global mapping of crustal and lithospheric thickness on Venus. J. Geophys. Res. 111, E08006.

Barsukov, V.L., Basilevski, A.T., Burba, G.A., Bobina, N.N., Kryuchkov, V.P., 1986. The geology and geomorphology of the Venus surface as revealed by the radar images obtained by Veneras 15 and 16 . J. Geophys. Res. 91, 378-398.

Basilevski, A.T., Head, J.W., 1995. Global stratigraphy of Venus: analysis of a random sample of thirty-six areas. Earth Moon Planets 66, 285-336.

Basilevski, A.T., Pronin, A.A., Ronca, L.B., Kryuchkov, V.P., Sukhanov, A.L., Markov, M.S., 1986. Styles of tectonic deformation on Venus: analysis of Venera 15 and Venera 16 data. J. Geophys. Res. 91, 399-411.

Beardsmore, G.R., Cull, J.P., 2001. Crustal Heat Flow: A Guide to Measurement and Modelling. Cambridge University Press, Cambridge, $324 \mathrm{pp}$.

Bindschadler, D.L., Parmentier, E.M., 1990. Mantle flow tectonics: the influence of a ductile lower crust and implications for the formation of topographic uplands on Venus. J. Geophys. Res. 95, 21,329-21,344.

Bindschadler, D.L., Schubert, G., Kaula, W.M., 1992. Coldspot and hotspots: global tectonics and mantle dynamic of Venus. J. Geophys. Res. 97, 13,495-13,532.

Bonner, J.L., Blackwell, D.D., Herrin, E.T., 2003. Thermal constraints on earthquake depths in California. Bull. Seismol. Soc. Am. 93, 2333-2354.

Brace, W.F., Kohlstedt, D.L., 1980. Limits on lithospheric strength stress imposed by laboratory experiments. J. Geophys. Res. 85, 6348-6352.

Brown, C.D., Grimm, R.E., 1997. Tessera deformation and the contemporaneous thermal state of the plateau highlands, Venus. Earth Planet. Sci. Lett. 147, 1-10.

Brown, C.D., Grimm, R.E., 1999. Recent tectonic and lithospheric thermal evolution of Venus. Icarus 139, 40-48.

Bullock, M.A., Grinspoon, D.H., 1996. The stability of climate on Venus. J. Geophys. Res. 101, 7521-7529.

Bullock, M.A., Grinspoon, D.H., 2001. The recent evolution of climate on Venus. Icarus 150, 19-37.

Cermak, V., 1993. Lithospheric thermal regimes in Europe. Phys. Earth Planet. Inter. 79, 179-193.

Corti, G., 2005. Dynamics of periodic instabilities during stretching of the continental lithosphere: view from centrifuge models and comparison with natural examples. Tectonics 24, TC2008.

Fletcher, R.C., Hallet, B., 1983. Unstable extension of the lithosphere: a mechanical model for basin-and-range structure. J. Geophys. Res. 88, 7457-7466.

Ghent, R.R., Hansen, V., 1999. Structural and kinematic analysis of eastern Ovda Regio, Venus: implications for crustal plateau formation. Icarus 139, 116-136.

Ghent, R.R., Tibuleac, I.M., 2002. Ribbon spacing in Venusian tessera: implications for layer thickness and thermal state. Geophys. Res. Lett. 29, 2000 .

Ghent, R.R., Phillips, R.J., Hansen, V.L., Nunes, D.C., 2005. Finite element modeling of short-wavelength folding on Venus: implications for the plume hypothesis for crustal plateau formation. J. Geophys. Res. 110, E11006. 
Gilmore, M.S., Collins, G.C., Ivanov, M.A., Marinangeli, L., Head, J.W., 1998. Style and sequence of extensional features in tessera terrain, Venus. J. Geophys. Res. 103, 16,813-16,840.

Grimm, R.E., 1994. Recent deformation rates on Venus. J. Geophys. Res. 99, 23, 163-23, 171.

Grimm, R.E., Hess, P.C., 1997. The crust of Venus. In: Bougher, S.W., Hunten, D.M., Phillips, R.J. (Eds.), Venus II. Univ. of Arizona Press, Tucson, pp. 1205-1244.

Hansen, V.L., 2006. Geologic constraints on crustal plateau surface histories, Venus: the lava pond and bolide impact hypotheses. J. Geophys. Res. 111, E11010.

Hansen, V.L., Willis, J.J., 1996. Structural analysis of a sampling of tesserae: implications for Venus geodynamics. Icarus 123, 296-312.

Hansen, V.L., Willis, J.J., 1998. Ribbon terrain formation, southwestern Fortuna Tessera, Venus: implications for lithosphere evolution. Icarus 132, 321-343.

Hansen, V.L., Willis, J.J., Banerdt, W.B., 1997. Tectonic overview and synthesis. In: Bougher, S.W., Hunten, D.M., Phillips, R.J. (Eds.), Venus II. University of Arizona Press, Tucson, pp. 797-844.

Hansen, V.L., Banks, B.K., Ghent, R.R., 1999. Tessera terrain and crustal plateaus, Venus. Geology 27, 1071-1074.

Hansen, V.L., Phillips, R.J., Willis, J.J., Ghent, R.R., 2000. Structures in tessera terrain, Venus: issues and answers. J. Geophys. Res. 105, 4135-4152.

Ivanov, M.A., Head, J.W., 1996. Tessera terrain on Venus: a survey of the global distribution, characteristics, and relation to surrounding units from Magellan data. J. Geophys. Res. 101, 14,861-14,908.

Kaula, W.M., 1990. Venus: a contrast in evolution to Earth. Science 270, 1191-1196.

Mackwell, S.J., Zimmerman, M.E., Kohlstedt, D.L., 1998. Hightemperature deformation of dry diabase with application to tectonics on Venus. J. Geophys. Res. 103, 975-984.

Martinod, J., Davy, P., 1992. Periodic instabilities during compression or extension of the lithosphere. 1. Deformation modes from an analytical perturbation method. J. Geophys. Res. 97, 1999-2014.

McDonough, W.F., Sun, S.S., 1995. The composition of the Earth. Chem. Geol. 120, 223-253.

McKinnon, W.B., Zhanle, K.J., Ivanov, B.A., Melosh, J.H., 1997. Cratering on Venus: models and observations. In: Bougher, S.W., Hunten, D.M., Phillips, R.J. (Eds.), Venus II. University of Arizona Press, Tucson, pp. 969-1014.

Montési, L.G.J., Zuber, M.T., 2002. Revisiting the origin of tectonic spacing on Venus: importance of localization and surface temperature. In: Proceedings Lunar Planetary Science Conference 33th, Abstract 1618.

Newman, R., White, N., 1997. Rheology of the continental lithosphere inferred from sedimentary basins. Nature 385, 621-624.

Nunes, D.C., Phillips, R.J., Brown, C.D., Dombard, A.J., 2004. Relaxation of compensated topography and the evolution of crustal plateaus on Venus. J. Geophys. Res. 109, E01006.

Phillips, R.J., Hansen, V.L., 1998. Geological evolution of Venus: rises, plains, plumes, and plateaus. Science 279, 1492-1497.

Phillips, R.J., Grimm, R.E., Malin, M.C., 1991. Hot-spot evolution and the global tectonics of Venus. Science 252, 651-658.
Phillips, R.J., Johnson, C.L., Mackwell, S.J., Morgan, P., Sandwell, D.T., Zuber, M.T., 1997. Lithospheric mechanics and dynamics of Venus. In: Bougher, S.W., Hunten, D.M., Phillips, R.J. (Eds.), Venus II. University of Arizona Press, Tucson, pp. 1163-1204.

Phillips, R.J., Bullock, M.A., Hauck II, S.A., 2001. Climate and interior coupled evolution on Venus. Geophys. Res. Lett. 28, 1779-1782.

Pollack, H.N., Hunter, S.J., Johnson, J.R., 1993. Heat flow from the Earth interior: analysis of the global data set. Rev. Geophys. 31, 267-280.

Price, M., Suppe, J., 1994. Mean age of rifting and volcanism on Venus deduced from impact craters densities. Nature 372, 756-759.

Ruiz, J., 2003. Heat flow and depth to a possible internal ocean on Triton. Icarus $166,436-439$.

Ruiz, J., Tejero, R., 2000. Heat flows through the ice lithosphere of Europa. J. Geophys. Res. 105, 23,283-23,289.

Ruiz, J., McGovern, P.J., Tejero, R., 2006a. The early thermal and magnetic state of the cratered highlands of Mars. Earth Planet. Sci. Lett. 241, 2-10.

Ruiz, J., Tejero, R., McGovern, P.J., 2006b. Evidence for a differentiated crust at Solis Planum, Mars, from lithospheric strength and heat flow. Icarus $180,308-313$.

Schubert, G., Solomatov, V.S., Tackley, P.J., Turcotte, D.L., 1997. Mantle convection and the thermal evolution of Venus. In: Bougher, S.W., Hunten, D.M., Phillips, R.J. (Eds.), Venus II. University of Arizona Press, Tucson, pp. 1245-1287.

Simons, M., Solomon, S.C., Hager, B.H., 1997. Global variations in the geoid/topography admittance of Venus. Geophys. J. Int. 131, 24-44.

Smith, R.B., 1977. Formation of folds, boudinage and mullions in nonNewtonian materials. Geol. Soc. Am. Bull. 88, 312-320.

Smrekar, S.E., Phillips, R.J., 1991. Venusian highlands: geoid to topography ratios and their implications. Earth Planet. Sci. Lett. $107,582-597$.

Solomatov, V.S., Moresi, L.N., 1996. Stagnant lid convection on Venus. J. Geophys. Res. 101, 4737-4753.

Solomon, S.C., Head, J.W., 1982. Mechanics for lithospheric heat transport on Venus: implications for tectonic style and volcanism. J. Geophys. Res. 87, 9236-9246.

Surkov, Y.A., Kirnozov, F.F., Glazov, V.N., Dunchenko, A.G., Tatsy, L.P., Sobornov, O.P., 1987. Uranium, thorium, and potassium in the Venusian rocks at the landing sites of Vega-1 and Vega-2. J. Geophys. Res. 92, 537-540.

Turcotte, D.L., 1995. How does Venus lose heat? J. Geophys. Res. 100, $16,931-16,940$.

Turcotte, D.L., Schubert, G., 2002. Geodynamics, second ed. Cambridge University Press, Cambridge, 462pp.

Watts, A.B., 2001. Isostasy and Flexure of the Lithosphere. Cambridge University Press, Cambridge, 458pp.

Yasuda, A., Fujii, T., Kurita, K., 1994. Meeting phase relations of an anhydrous mid-ocean ridge basalt from 3 to $20 \mathrm{GPa}$ : implications for the behavior of subducted oceanic crust in the mantle. J. Geophys. Res. 99, 9401-9414.

Zuber, M.T., Parmentier, E.M., Fletcher, R.C., 1986. Extension of continental lithosphere: a model for two scales of Basin and Range deformation. J. Geophys. Res. 91, 4826-4838. 